\title{
Copper ion-catalyzed regioselective introduction of active methylene groups into the $\gamma$-position of piperidine skeleton and its application to synthesis of (-)-cincholoiponic acid
}

\author{
Daishirou Minato, Mieko Imai, Yasuhisa Kanda, Osamu Onomura, \\ and Yoshihiro Matsumura* \\ Department of Pharmaceutical Sciences, Graduate School of Biomedical Sciences, Nagasaki \\ University, 1-14 Bunkyo-machi, Nagasaki 852-8521, Japan
}

\begin{abstract}
Copper ion-catalyzed regioselective introduction of active methylene groups into the $\gamma$-position of piperidine skeleton was exploited. In the case of using chiral ligand as an additive, this reaction proceeded with moderate enantioselectivities. This method was applied to synthesis of (-)-cincholoiponic acid from $N$-methoxycarbonylpiperidine.
\end{abstract}

Carbon-carbon bond forming reactions at the $\alpha$-position of cyclic amines $\mathbf{1}$ through iminium ion intermediates $\mathbf{A}$ to afford $\alpha$-alkylated cyclic amines $\mathbf{3}$ have attracted a lot of interest (Eq. (1)) since it provides one of the simplest routes for formation of $\mathbf{3}$ which are often found as important moiety of naturally occurring nitrogen heterocycles. ${ }^{1}$ We have already exploited electrochemical oxidation method through $\alpha$-methoxylated piperidine 2 for the route. ${ }^{2}$

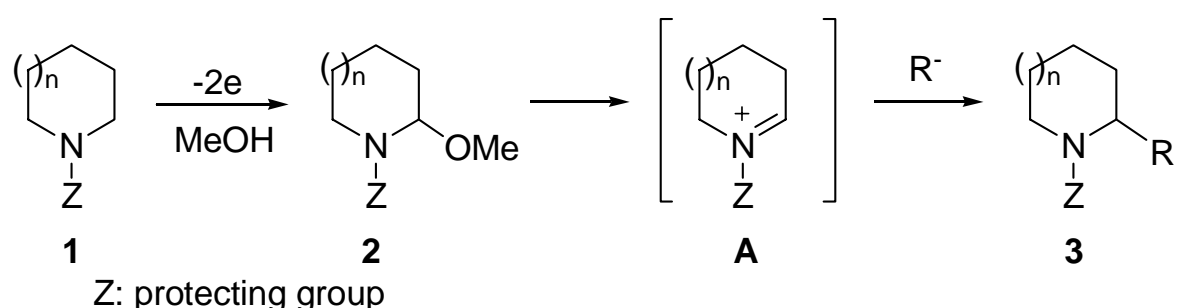

On the other hand, there have been only two methods for carbon-carbon bond forming reaction at the $\gamma$-position of $\mathbf{1}$, though $\gamma$-substituted piperidines are also worthwhile as synthetic intermediates for a variety of natural products and drug candidates. ${ }^{3}$ One is conjugate addition of some aryl groups to $\beta, \gamma$-didehydro- $\alpha$-oxopiperidines, ${ }^{3 e, g, i}$ and the other is introduction of some nucleophiles to pyridinium salts. ${ }^{4,5,6}$ These methods however, are not applicable to piperidine derivatives possessing functionalized alkyl group at the $\gamma$-position, such as (-)-cincholoiponic acid (cis-1), (Fig. 1), ${ }^{7}$ which is a structural moiety in a variety of alkaloids, and any asymmetric alkylation has not been reported. ${ }^{8}$

This paper presents copper ion-catalyzed coupling reaction of $\alpha$-methoxylated $\beta, \gamma$-didehydropiperidines $\mathbf{6}$ with active methylene compounds $\mathbf{7}$ to afford $\gamma$-substituted piperidines 9 without formation of undesired regioisomers 8 (Eq. (2) $)^{9,10}$ and its asymmetric application leading to formal synthesis of optically active cis-1 with

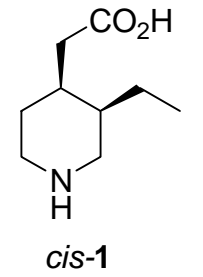

Figure 1

Key words: piperidine, nucleophlic substitution, copper, regioselective, asymmetric

*Corresponding author, Tel +81-95-819-2429, Fax +81-95-819-2476, E-mail matumura@ net.nagasaki-u.ac.jp (Y. Matsumura). 
moderate enantioselectivity. The key starting compounds $\mathbf{6 a}, \mathbf{b}\left(\mathbf{a}^{11} ; \mathrm{R}=\mathrm{H}, \mathbf{b}^{12} ; \mathrm{R}=\mathrm{Et}\right)$ are known to be prepared by electrochemical oxidation of $N$-methoxycarbonylpiperidine (4) through $\alpha$-methoxylated piperidine 5 . $^{13}$

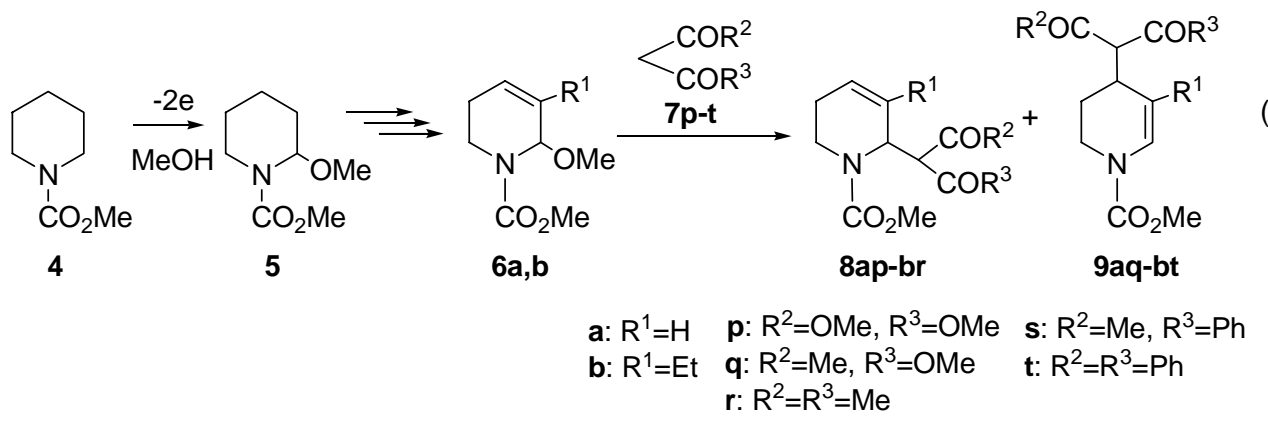

With $\mathbf{6 a}, \mathbf{b}$, we first tried the coupling reaction of $\mathbf{6 a}, \mathbf{b}$ with dimethyl malonate (7p), methyl acetoacetate (7q), and 1,3-diketones 7r-t and found that the coupling reaction proceeded in the presence of $\mathrm{Cu}(\mathrm{OTf})_{2}$ ( $5 \mathrm{~mol} \%$ ) in THF at room temperature for $12 \mathrm{hrs}$ to afford $\alpha$-substituted piperidines 8ap-br and/or selectively $\gamma$-substituted piperidines 9aq-bt, the ratio being dependent on the structures of $\mathbf{6}$ and of nucleophiles 7. The results are shown in Table 1.

Table 1. The reaction of $\mathbf{6 a}, \mathbf{b}$ with various active methylene compounds $7 \mathbf{p}-\mathrm{t}^{\mathrm{a}}$

\begin{tabular}{|c|c|c|c|c|c|c|c|c|c|c|}
\hline \multirow{3}{*}{$\frac{\text { entry }}{1}$} & \multicolumn{2}{|c|}{ substrate } & \multicolumn{4}{|c|}{ active methylene compound } & \multirow{2}{*}{\multicolumn{2}{|c|}{$\begin{array}{l}\text { product } 8,9 \\
\text { yield (\%) }\end{array}$}} & \multirow{2}{*}{\multicolumn{2}{|c|}{$\begin{array}{l}\text { ratio } \\
8 / 9\end{array}$}} \\
\hline & $6 a, b$ & $\mathrm{R}^{1}$ & $7 p-t$ & $\mathrm{R}^{2}$ & & & & & & \\
\hline & $6 a$ & $\mathrm{H}$ & $7 p$ & $\mathrm{OMe}$ & $\mathrm{OMe}$ & 8ap & 68 & 9ap & 0 & $100 / 0$ \\
\hline 2 & $6 b$ & Et & $7 p$ & $\mathrm{OMe}$ & $\mathrm{OMe}$ & $8 \mathrm{bp}$ & 70 & $9 b p$ & 11 & $89 / 11$ \\
\hline 3 & $6 a$ & & $7 q$ & Me & OMe & $8 a q^{b}$ & 41 & $9 a q^{b}$ & 21 & $66 / 34$ \\
\hline 4 & $6 b$ & & $7 q$ & $\mathrm{Me}$ & OMe & $8 \mathrm{bq}$ & 0 & $9 b q^{b}$ & 85 & $0 / 100$ \\
\hline 5 & $6 b$ & & $7 r$ & $\mathrm{Me}$ & $\mathrm{Me}$ & $8 b r$ & 12 & $9 b r$ & 37 & $25 / 75$ \\
\hline 6 & $6 b$ & & $7 s$ & $\mathrm{Me}$ & $\mathrm{Ph}$ & $8 \mathrm{bs}$ & 0 & $9 b s^{b}$ & 55 & $0 / 100$ \\
\hline 7 & $6 b$ & & $7 t$ & $\mathrm{Ph}$ & $\mathrm{Ph}$ & $8 b t$ & 0 & $9 b t$ & 48 & $0 / 100$ \\
\hline $8^{c}$ & $6 b$ & & $7 q$ & $\mathrm{Me}$ & OMe & $8 b q^{b}$ & 22 & $9 b q^{b}$ & 6 & $77 / 23$ \\
\hline
\end{tabular}

The observed regioselectivity $(\mathbf{8} / \mathbf{9})$ was noticeable. Dimethyl malonate $(\mathbf{7 p})$ as a nucleophile afforded $\alpha$-substituted piperidines ( $8 \mathbf{a p}$ and $\mathbf{8 b p}$ ) exclusively for $\mathbf{6 a}$ (entry 1 ) and mainly for $\mathbf{6 b}$ (entry 2), whereas the use of methyl acetoacetate (7q) decreased the ratio of $\mathbf{8 / 9}$ for $\mathbf{6 a}$ (entry 3) and eventually resulted in formation of only $\mathbf{9 b q}$ for $\mathbf{6 b}$ (entry 4). Also a predominant formation of $\mathbf{9 b r}-\mathbf{b t}$ was observed in the reaction of $\mathbf{6 b}$ with 1,3-diketones 7r-t (entries 5-7), though the yields of the products were in general lower than those in cases using malonates and acetoacetates. ${ }^{14}$

In order to elucidate the mechanism for the high regioselectivity observed in the reaction of $\mathbf{6 b}$ and 
$\mathbf{7 q}$ (entry 4), the reaction was carried out at $0^{\circ} \mathrm{C}$ to afford a mixture of $\mathbf{8 b q}$ and $\mathbf{9 b q}$ with a ratio of $77 / 23$ in low yield (entry 8), whereas the treatment of a mixture of $\mathbf{8 b q}$ and $\mathbf{9 b q}(\mathbf{8 b q} / \mathbf{9 b q}=77 / 23)$ with $\mathrm{Cu}(\mathrm{OTf})_{2}$ in THF at room temperature resulted in an exclusive formation of $\mathbf{9 b q}$ (Eq. (3)).

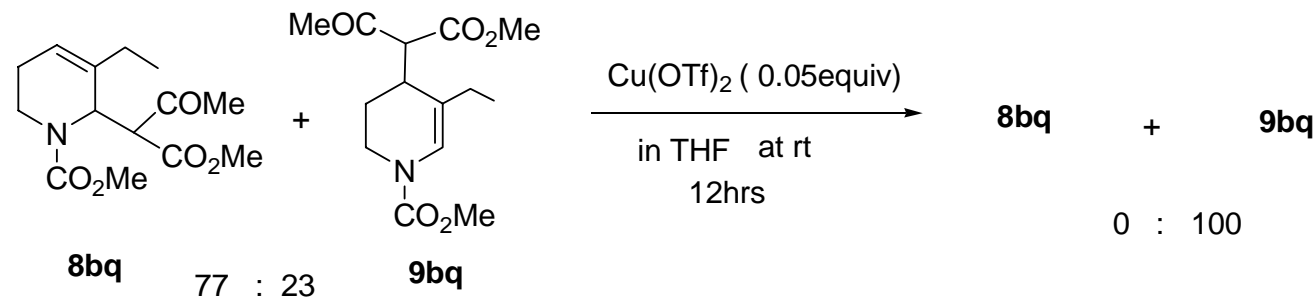

The selectivity can be explained in terms of the steric factor of both substrates and active methylene compounds as described later.

After finding the best conditions that $\gamma$-substituted piperidine $\mathbf{9 b q}$ was selectively formed, we then tried asymmetric reaction of $\mathbf{6} \mathbf{b}$ with $\mathbf{7 q}$ in the presence of $\mathrm{Cu}(\mathrm{OTf})_{2}$ and chiral bisoxazoline ligand L. ${ }^{15}$ The result was interesting since a mixture of diastereomers $9 \mathbf{b q} *$ was generated in a ratio of 56/44, each of which had modest optical purity (43 44\% ee) (Eq. (4)). However, asymmetric reaction was not observed in $\mathrm{MeCN}$ in place of THF as a solvent.

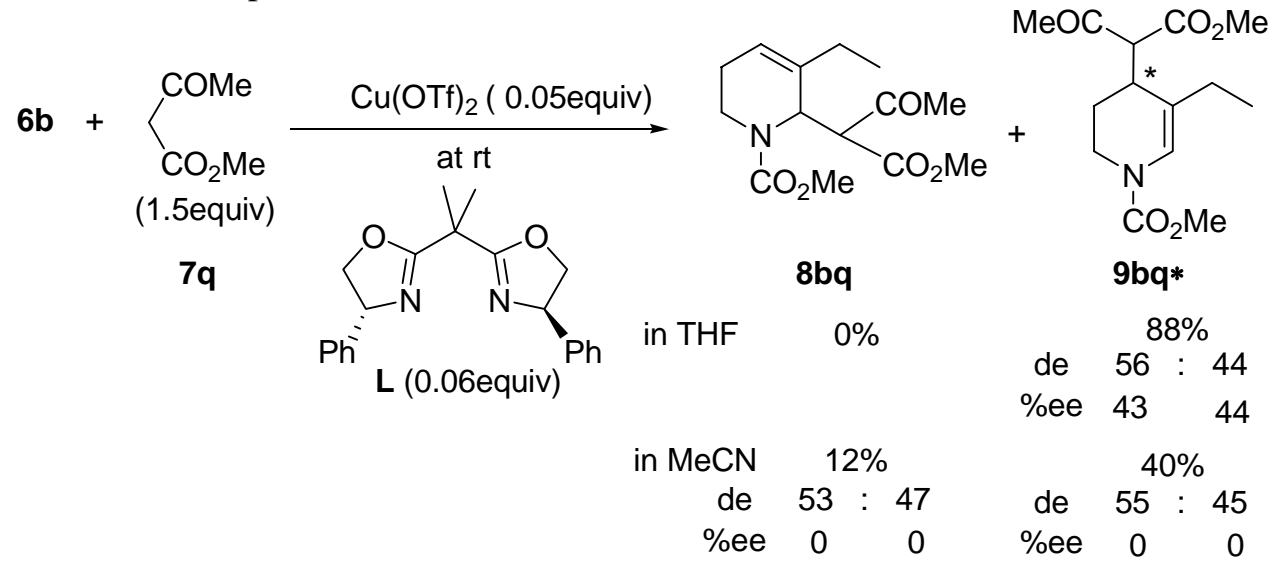

Further information to support the reaction mechanism was obtained when racemic $\alpha$-substituted piperidine $\mathbf{8 b q}$ was treated with $\mathrm{Cu}(\mathrm{OTf})_{2}$ in the presence of chiral ligand $\mathbf{L}$ in $\mathrm{THF}$ at room temperature. The product was $\mathbf{9 b q *}$ in a quantitative yield, and each of the diastereomers was optically active (Eq. (5)).

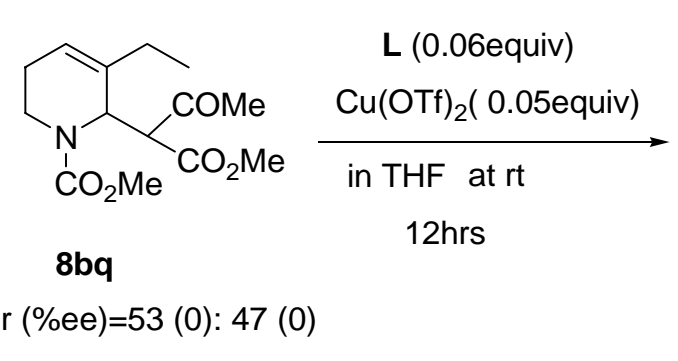<smiles>CCC1=CN(C(=O)O[Na])CCC1C(C(C)=O)C(C)=O</smiles>

$\operatorname{dr}(\%$ ee) $=51$ (37): 49 (34) 
These results strongly suggest that $\mathbf{8 b q}$ is a kinetically controlled product, while $\mathbf{9 b q}$ is a thermodynamically stable product, and the rearrangement of $\mathbf{8 b q}$ into $\mathbf{9 b q} *$ proceeds through an iminium ion $\mathbf{A b}$ with an intermolecular mechanism (Scheme 1). The observed regioselectivity may be determined by the steric factor of both $\beta$-ethyl substituent of $\mathbf{6 b}$ and nucleophiles $\mathbf{7 p}$-t, though the effect of the reactivity of nucleophiles on the regioselectivity is not ruled out.

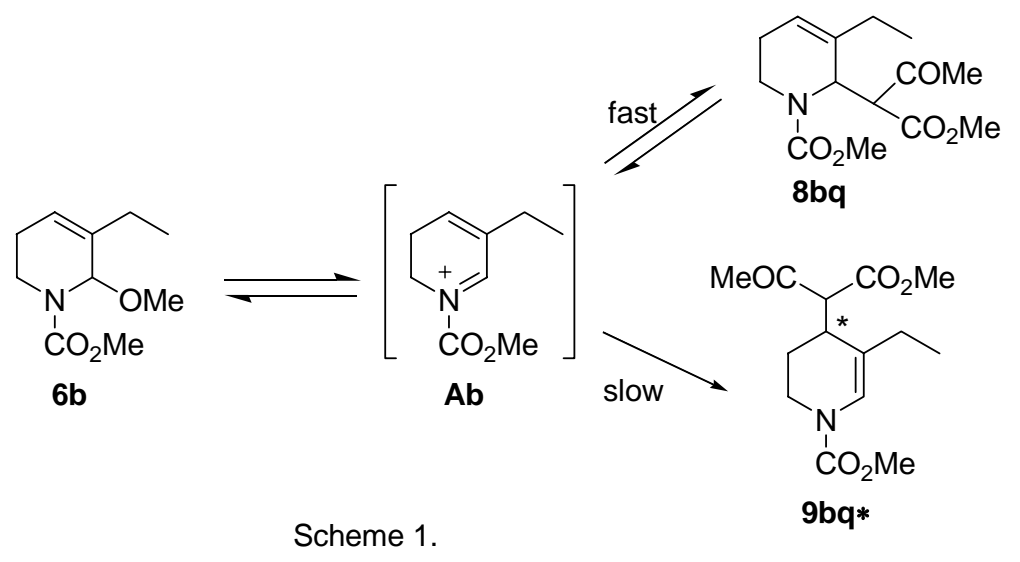

Finally, transformation of optically active 9bq* into cincholoiponic acid methyl ester $\mathrm{HCl}$ salt $\left(\right.$ cis-12) $^{16}$ was achieved by the method described in Eq. (6), and the absolute configuration at the $\gamma$-position of cis-12, that is, the $\gamma$-position of $9 \mathbf{b q *}$, was determined to be $S$ by the comparison of the product cis-12 with the authentic sample. ${ }^{7 a}$ It is known that the cis-12 is easily transformed into (-)-cincholoiponic acid (cis-1). ${ }^{7 \mathrm{a}}$

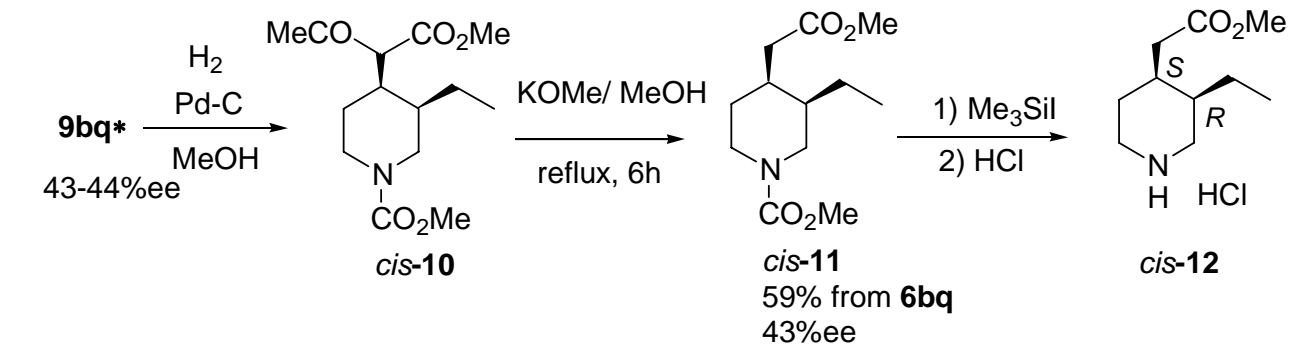

In $\gamma$-position of piperidine skeleton and its application to the formal synthesis of (-)-cincholoiponic acid (cis-1).

Further studies on mechanistic aspects and the improvement of \%ee are currently underway.

\section{Acknowledement}

This study was supported by a Grant-in-Aid for Scientific Research on Priority Areas, (No. 420: Reaction Control of Dynamic Complexes) from the Ministry of Education, Science, Sports and Culture, Japan and by a Grant-in-Aid for Scientific Research (C) (No. 15550094) from Japan Society for the Promotion of Science.

\section{References and Notes}

1. a) Speckamp, W. N.; Moolenaar, M. J. Tetrahedron 2000, 56, 3817-3856. b) Loh, T.-P.; Lye, 
P.-K.; Wang, R.-B.; Sim, K.-Y. Tetrahedron Lett. 2000, 41, 7779-7783. c) Okitsu, O.; Suzuki, R.; Kobayashi, S. J. Org. Chem. 2001, 66, 809-823. d) Albrecht, U.; Armbrust, H.; Langer, P. Synlett 2004, 143-145.

2. a) Shono, T.; Matsumura, Y.; Tsubata, K. J. Am. Chem. Soc.,1981, 103, 1172-1176. b) Shono, T.; Matsumura, Y.; Tsubata, K. Org. Synth. 1984, 63, 206-213; 1990, Coll. Vol. VII, 307-312. c) Matsumura, Y.; Kanda, Y.; Shirai, K.; Onomura, O.; Maki, T. Org. Lett. 1999, 1, 175-178. d) Onomura, O.; Ikeda, T.; Matsumura, Y. Heterocycles 2005, 66, 81-86. e) Matsumura, Y.; Ikeda, T.; Onomura, O. Heterocycles 2006, 67, 113-117.

3. For recent examples, see: a) Watson, P. S.; Jiang, B.; Scott, B. Org. Lett. 2000, 2, 3679-3681. b) Bowley, M.; Hallett, D. J.; Goodacre, S.; Moyes, C.; Crawforth, J.; Sparey, T. J.; Patel, S.; Marwood, R.; Patel, S.; Thomas, S.; Hitzel, L.; O'Connor, D.; Szeto, N.; Castro, J. L.; Hutson, P. H.; MacLeod A. M. J. Med. Chem. 2001, 44, 1603-1614. c) Thomas, J. B.; Atkinson, R. N.; Rothman, R. B.; Fix, S. E.; Mascarella, S. W.; Vinson, N. A.; Xu, H.; Dersch, C. M.; Lu, Y. -F.; Cantrell, B. E.; Zimmerman, D. M.; Carrol, F. I. J. Med. Chem. 2001, 44, 2687-2690. d) Agami, C.; Bisaro, F.; Comesse, S.; Guesné, S.; Kadouri-Puchot, C.; Morgentin, R. Eur. J. Org. Chem. 2001, 2385-2389. e) Senda, T.; Ogasawara, M.; Hayashi, T. J. Org. Chem. 2001, 66, 6852-6856. f) Reilly, M.; Anthony, D. R.; Gallagher, C. Tetrahedron Lett. 2003, 44, 2927-2930. g) Murthy, K. S. K.; Rey, A. W.; Tjepkema, M. Tetrahedron Lett. 2003, 44, 5355-5358. h) Gill, C. D.; Greenhalgh, D. A.; Simpkins, N. S. Tetrahedron 2003, 59, 9213-9230. i) Ecija, M.; Diez, A.; Rubiralta, M.; Casamitjana, N.; Kogan, M. J.; Giralt, E. J. Org. Chem. 2003, 68, 9541-9553. j) Raheem, I. T.; Goodman, S. N.; Jacobsen, E. N. J. Am. Chem. Soc. 2004, 126, 706-707. k) Tanaka, K.; Kobayashi, T.; Mori, H.; Katsumura, S. J. Org. Chem. 2004, 69, 5906-5925. 1) Mi, Y.; Corey, E. J. Tetrahedron Lett. 2006, 47, 2515-2516. m) Solares, L. F.; Lavandera, I.; Gotor-Fernández, V.; Brieva, R.; Gotor, V. Tetrahedron 2006, 66, 3284-3291.

4. Addition to pyridinium salts, see: a) Wenkert, E.; Chang, C.-J.; Chawla, H. P. S.; Cochran, D. W.; Hagaman, E. W.; King, J. C.; Orito, K. J. Am. Chem. Soc. 1976, 98, 3645-3655. b) Alvarez, M.; Lavilla, R.; Bosch, J. Tetrahedron Lett. 1987, 28, 4457-4460.

5. Addition to $N$-acyl pyridinium salts, see: a) Akiba, K.; Matsuda, H.; Wada, M. Tetrahedron Lett. 1981, 22, 4093-4096. b) Comins, D. L.; Abdullah, A. H. J. Org. Chem. 1982, 47, 4315-4319. c) Yamaguchi, R.; Nakazono, Y.; Kawanishi, M. Tetrahedron Lett. 1983, 24, 1801-1804. d) Wang, X.; Kauppi, A. M.; Olsson, R.; Almqvist, F. Eur. J. Org. Chem. 2003, 4586-4592.

6. Addition to 5,6-dihydropyridinium salts, see: a) Grierson, D. S.; Harris, M.; Husson, H. P. Tetrahedron 1983, 39, 3683-3694. Allylation, see: b) Comins, D. L.; Baevsky, M. F.; Hong, H. J. Am. Chem. Soc. 1992, 114, 10972-10974.

7. a) Uskokovic, M. R.; Henderson, T.; Reese, C.; Lee, H. L.; Grethe, G.; Gutzwiller, J. J. Am. Chem. Soc. 1978, 100, 571-576. b) Brown, R. T.; Leonard, J. Tetrahedron Lett. 1978, 1605-1608. c) Fujii, T.; Ohba, M. Chem. Pharm. Bull. 1985, 33, 583-590. d) Hirai, Y.; Terada, T.; Yamazaki, T.; Momose, T. J. Chem. Soc., Perkin Trans. 1 1992, 517-524. e) Ihara, M.; Taniguchi, N.; Fukumoto, K. J. Chem. Soc., Perkin Trans. 1 1997, 365-369. f) Amat, M.; Pérez, M.; Llor, N.; Bosch, J. Org. Lett. 2002, 4, 2787-2790.

8. Catalytic asymmetric alkylation at the 2-position of piperidine skeleton have been already reported by us, see: a) Onomura, O.; Kanda, Y.; Nakamura, Y.; Maki, T.; Matsumura, Y. Tetrahedron Lett. 2002, 43, 3229-3231. b) Kanda, Y.; Onomura, O.; Maki, T.; Matsumura, Y. Chirality 2003, 15, 89-94. c) Onomura, O.; Kanda, Y.; Imai, M.; Matsumura, Y. Electrochimica Acta 2005, 50, 4926-4935.

9. Copper ion-catalyzed alkylation and phenylation, see: Shono, T.; Terauchi, J.; Ohki, Y.; 
Matsumura, Y. Tetrahedron Lett. 1990, 31, 6385-6386.

10. Titanium-catalyzed diastereoselective introduction of sterically hindered active methylene groups, see: Matsumura, Y.; Yoshimoto, Y.; Horikawa, C.; Maki, T.; Watanabe, M. Tetrahedron Lett. 1996, 37, 5715-5718.

11. a) Shono, T.; Matsumura, Y.; Onomura, O.; Yamada, Y. Tetrahedron Lett. 1987, 28, 4073-4074. b) Matsumura, Y.; Onomura, O.; Suzuki, H.; Furukubo, S.; Maki, T.; Li, C.-J. Tetrahedron Lett. 2003, 44, 5519-5522.

12. Shono, T.; Matsumura, Y.; Ogaki, M.; Onomura, O. Chem. Lett. 1987, 1447-1450.

13. Shono, T.; Hamaguchi, H.; Matsumura, Y. J. Am. Chem. Soc. 1975, 97, 4264-4268.

14. Table 1 shows only the yields of major products.

15. A typical experimental procedure: A solution of methyl acetoaceate $(\mathbf{7 q})(0.75 \mathrm{mmol}), \mathrm{Cu}(\mathrm{OTf})_{2}$ $(0.025 \mathrm{mmol})$ and chiral ligand $\mathbf{L}(0.03 \mathrm{mmol})$ in THF $(1 \mathrm{~mL})$ was stirred for $5 \mathrm{~min}$ at room temperature under a nitrogen atmosphere. Into the solution was added a solution of $\mathbf{6 b}(0.5 \mathrm{mmol})$ in THF ( $1 \mathrm{~mL})$. After stirring for $12 \mathrm{hrs}$, the resulting mixture was poured into aqueous $\mathrm{NaHCO}_{3}$ $(5 \mathrm{~mL})$. The organic portion was extracted with AcOEt $(10 \mathrm{~mL} \times 3)$ and dried over $\mathrm{MgSO}_{4}$. The resulting solution was concentrated in vacuo. The residue was chromatographed on silica gel (hexane/AcOEt $=5 / 1)$ to afford 9bq* $(88 \%$ yield, diastereomer ratio $=56(43 \%$ ee $): 44(44 \%$ ee $)$ ).

16. cis-12 (recrystallization from $\mathrm{MeOH}-$ Acetone): $[\alpha]^{29}-8.8$ (c 2.5, MeOH) $\left[\right.$ lit. $^{7 \mathrm{a}}[\alpha]^{29} \mathrm{D}-8.3$ (c 1.0, $\mathrm{MeOH})]$. 